\title{
Integrated Design and Control of Renewable Energy Sources for Energy Management
}

\author{
Teki Vamsee Krishna \\ School of Electrical Engineering \\ Kalinga Institute of Industrial \\ Technology Deemed to be University \\ Bhubaneswar, India \\ vamsi.teki239@gmail.com
}

\author{
Manoj Kumar Maharana \\ School of Electrical Engineering \\ Kalinga Institute of Industrial \\ Technology Deemed to be University \\ Bhubaneswar, India \\ mkmfel@kiit.ac.in
}

\author{
Chinmoy Kumar Panigrahi \\ School of Electrical Engineering \\ Kalinga Institute of Industrial \\ Technology Deemed to be University \\ Bhubaneswar, India \\ panigrahichinmoy@gmail.com
}

\begin{abstract}
Growing population and expanding industry set off the demand for electrical energy and issues, such as the problem of peak load demand, emerge. To balance the supply and load demand problem, the energy management system has the vital role of Electric Peak shaving with the integration of microgrid into the utility grid. The combination of demand-side management with storable energy sources helps us resolve the matters concerned with the peak load demand. However, in a microgrid, whenever the distributed energy sources are interconnected, the DC bus link voltage will vary due to the inherent behavior of each source as they mainly depend on geographical conditions. This work proposes voltage droop control strategy to keep the DC bus link voltage at a constant value. Also, it gives an overlook of the present power sector scenario of India and a reassessment of the demand side management system and how it is utilized in electrical peak shaving.
\end{abstract}

Keywords-demand side management; droop controller; energy management system; microgrid; peak load demand

\section{INTRODUCTION}

Electrical energy is the backbone and the most essential factor for world growing technology and economic development. Load demand due to generation and consumption mismatch problems is a major issue of the perpetually expanding utility grid. With the help of the available fossil fuels to generate adequate power to satisfy the load demand, the problem of greenhouse gas emissions emerged. Overcoming issues like greenhouse gas emissions, led to the utilization of Renewable Energy Sources (RESs) for electrical energy generation. We use RESs to reduce the problem of demand requirement that occurs due to the mismatch in generation and consumption. Globally, over $70 \%$ of generation is done by using fossil fuels like (coal, oil, nuclear, etc.), while in India the percentage is $80 \%$ [1]. The supply demand may increase up to $40-50 \%$ in the next one or two decades. If the energy demand increases gradually in the next few decades, the energy generation by using the bulk amount of fossil fuels is not a feasible solution, because these sources may drain quickly and by using fuels like coal for power generation in thermal power plants will release more amount of pollutant gases like $\mathrm{SO}_{2}$ and $\mathrm{NO}_{\mathrm{x}}$. Because of these pollutant gases, there is a change in environmental conditions. So to reduce these problems, RES have been utilised, and they are leaping power generation, especially sources like solar and wind energy system (excluding hydropower plants), having an ability to recharge at every time instant. However, at present in India, only $17 \%$ of the demand is supplied by RESs, even though the scope and ability to increase the generation of renewable energy exist. RESs take an all-important share in India's energy generation sector [2]. However, due to their irregularity in nature, RESs do not always help in reducing the peak demand when generation and consumption mismatch problems occur. Even sometimes while penetrating to the grid, we can see the problem occurring due to the extensive integration of wind and solar generation in the distribution and transmission network. High solar irradiance and wind speed when the demand is low can cause issues like voltage regulation, frequency regulation, and system losses in the distribution and transmission networks [3]. Solutions for these issues should overcome by bringing into effective action the comparison of the Demand Side Management (DSM) and Energy Storage System (ESS). DSM provides a platform for peak demand by shifting loads from peak-time period to the off-peak-time period and also controls the loads during renewable energy generation. If the generation from RES is more than the demand, it manages the excess amount of energy generated by RESs by utilizing ESS, and the energy is pushed back to the utility grid during the peak period of the supply demand.

The DSM is not only used to reduce peak demand and shifting of loads but also to support distributed generation (microgrids) to consume the power generated by small-scale RESs for local loads instead of transmitting long distances. The ESS can offer high flexibility in a state of charging and discharging at the time of peak and off-peak periods so that the problem of demand in supply can be distributed equally. We can also use ESS to reduce fluctuations and issues regarding voltage and frequency regulation. In microgrids (MGs), when integrating two more sources, the main issue is the voltage regulation of the DC bus link voltage, which it cannot be kept consistent.

This study mainly focuses on maintaining voltage regulation and constant DC bus link voltage with the help of a 
voltage droop controller for power management when two energy sources (solar and wind energy with ESS) penetrate the system.

\section{LITERATURE REVIEW}

Energy Management System (EMS) plays a crucial role in present power systems. EMS is used to optimize the most complex and vital technical creations in the electrical power system. An essential step in energy management systems is operating different energy sources to overcome issues concerned with the mismatch of generation and consumption to reduce electrical peak shaving. EMS has taken various forms such as Generation Side Management (GSM), Industrial Energy Management System (IEMS), Demand-Side Management (DSM), Building Energy Management System (BEMS), Home Energy Management System (HEMS). However, when compared with other topologies, DSM plays the most vital role in the present power systems scenario with scheduling loads according to supply demand. The main aim of the DSM scheme is to get the final load curve as close as possible to the standard load curve. Combining DSM with an ESS allows reducing the mismatch problem and the fluctuations and frequency regulation when distribution generating units penetrate the utility grid.

There are some useful studies in the field of MGs and distribution generating units. Authors in [4] developed a smallscale MG-based hybrid system, consisting of solar and wind energy with a battery storage system. The operation of an MG by controlling different sources and with the help of an energy management algorithm verified with RTDS increased the system performance of the MG. They used a cascaded PI controller to control the DC link voltage by taking an average value and generating corresponding reference current signals to various converters. The drawback of the EMS method is that when the load demand increases, it dedicates the developed algorithm to the standalone system and exercises load shedding. Authors in [5] proposed deterministic energy management for MGs, used for feature solar photovoltaic with BSS installation, which gives more flexibility to the distribution network. The management has functioned in two parts according to their characteristics, but because of variations in geographical conditions, the output power from RES fluctuates, which results in the variation of grid's voltage and frequency regulations. To overcome these issues, the authors implemented a hybrid supercapacitor battery-based PV active generator to offer energy reserves with fewer fluctuations and to balance power fluctuations coming from the PV active generator and primary frequency control.

In EMS, DSM is the best field to optimize the problems related to peak demand. DSM has the potential to improve the energy system at the side of demand [6]. DSM's main advantage is that it is less expensive to influence the load intelligently by scheduling the load according to the demand and availability of supply (direct and indirect approach) instead of constructing new generating units or by providing the ESS. The indirect DSM approach is a time-varying price signal, which influences load according to the peak time, known as Demand Response (DR). We can remark it as complicated for the consumer end to use a time-varying tariff scheme, in a real- time pricing policy. In [7], a game-theoretic model was proposed to optimize the demand and to decrease the consumer's electricity bill around 20\%. DSM strategy is utilized to optimize resources with the game-theoretical model to schedule the appliances according to the Time Of Use (TOU). The control model optimizes the user's electricity bill, according to the TOU: in the peak period the prizes are high and vice versa. The biggest challenge with the implementation of the TOU is that a problem from the consumers end may emerge when the price is updated in every cycle, which may be more or less equal to 1 hour.

Spinning reverse is seen as the primary and secondary control, as the active output power directly depends on frequency. Grid state and frequency can be restored with added active power. The biggest challenge the power plants face is when, because of the loads, they act as a reverse or virtual negative spinning. Droop control or some other control management are used to correlate the power consumption with the grid state. An adaptive power flow control has been proposed in [8], used to reduce the electrical peak grid demand and to increase the penetration of RES to reduce the mismatch between generation and consumption. APFC aims to control the appliances, consuming the most amount of power and the BSS was charged or discharged according to the power demands. Integrating RES does not mean that it can reduce the peak demand at the time of imbalance between supply and demand. However, penetrating a high level of PV energy into a distribution network with strong irradiance and low demand can cause issues. Combing ESS with DSM is one of the best solutions in overcoming those issues. To get the benefits of the system, the authors have focused on control management. APFC uses the historical data on grid demand, PV data and load demand data as inputs to decide the DSM and battery charge or discharge mode to balance the demand and supply. Thus, the average peak demand was reduced to $35 \%$ and the share of PV generation was increased up to $64 \%$.

To reduce fluctuations requires storing energy to achieve proper regulation when penetrated with RES. Authors in [9] presented a power management and control technique for a standalone hybrid system with flywheel energy storage system usually alternating in nature. The controller output is the reference voltage, used to switch the power converter with space vector pulse width modulation to keep the DC bus link voltage. Frequency regulation used to be conducted by synchronous generators, but now it is gradually taken over by power converts as Virtual Synchronous Generators (VSGs) [10], which act as an interface between the RES and the utility grid. Droop and VSG controller were used to control the inner voltage. In modern power systems, power converters are used to transfer maximum power from RESs without frequency regulation. The hybrid energy storage system comprises of a battery and an ultra-capacitor to achieve power management. The authors of [10] did not consider the quick changes in the load demand situations though. In the future smart grid, DSM will play a vital role by scheduling and managing the loads in a smart way to reduce electrical peak demand. For scheduling appliances, authors in [11] used an evolutionary DSM- based algorithm for scheduling loads of end users according to the demand. To reduce issues like peak demand, they develop two 
approaches for promoting energy-efficient technology, later known as DR. A new Home Energy System (HES) model based on TOU scheme was developed with and without RESs, to reduce electrical peak demand. The authors did not discuss the benefits of load scheduling of multiple houses to utility and end-user comfort, addressing the case of a single house instead.

Distributed EMSs become more popular for smart appliance scheduling. When the demand varies regarding time, the use of a BSS is studied to decrease the cost of the demand for consumers. However, variations to the supply and demand (especially when dealing with RESs), effect the action of charging and discharging efficiency of storage devices, reducing DC bus link voltage at peak time which is not kept constant $[12,13]$. In [14], a droop control method is used for a standalone MG for EMS to support the generator output power for stable operation. The DC bus link voltage also kept constant by taking the reference value from the output voltage magnitude and phase angle. The droop controller identifies the reference values from two sets of specific droop characteristics to get optimal output power. The authors considered only the standalone system and did not discuss the operation of droop controller when it was operated in grid-connected mode and the benefits of controlling for reactive power-sharing. To reduce peak demand, a mixed-integer nonlinear programming technique was used in [15]. The authors developed an Adaptive Neural Fuzzy Inference System (ANFIS) based microcontroller to schedule the appliances according to the demand. We should remark that the overall control of the energy system becomes a big challenge and demand response is also not a fully automated solution for scheduling the appliances. In order to reduce power demand, one solution is to penetrate renewable sources to the utility grid. Authors in [16] did so considering solar energy only. In [17], Dynamic Programming (DP) was used for optimal power flow management, which helps in penetrating PV power to the utility grid for peak shaving. ESS is the best solution that reduces the fluctuations in output power. In this, they mainly concentrated on a small amount of energy with high peak demand, which can buffer by the battery storage system.

The literature review on demand-side management with the combination of energy storage systems gave some worth mentioning conclusions:

- When RESs penetrate the utility grid, the change in renewable generation and load can cause variation in DC bus link voltage.

- As the RESs are based on geographical conditions, they can cause issues like output power fluctuations, voltage and frequency regulation, and circulating current within the system.

- Droop control method is used to reduce the active and reactive power variation by taking reference set points from output voltage magnitude and frequency. It is also used to keep the sharing of reactive power in $\mathrm{AC} \mathrm{MG}$ at balance and maintain DC bus link voltage at its nominal value.

\section{ROLE AND CONTROL STRATEGY OF ENERGY MANAGEMENT}

In smart grids, EMS consists of functions used to monitor, measure, and control the supply of demand centrally [18-25]. EMS is used to forecast load data, operate and manage sources in order to reduce the supply demand. RESs are useful and helpful at the time of peak demand for electrical peak shaving, either connected to the distribution network (small-scale) or to the transmission, network (large scale). They also increase the complexity of the network to supply uninterrupted power to load. However, the integration of large-scale renewable energy to the utility grid creates challenges to the traditional grid as these depend on weather conditions. The development in EMS will reduce the issues when RESs are integrated. Renewable energy generation, such as solar, wind, etc., is formed as an $\mathrm{MG}$, taking an essential role in the EPS to produce energy with the other generating units (coal, nuclear, etc.) for reducing peak demand. These energy sources with a combination of ESS, power converters and communication between sources made the grid power system network more complicated. To increase power system network stability and controllability requires many communications links and data, creating communication burdens and decreasing the protection scheme's performance. Nowadays, with the smart grid utilization, household-level distributed EMS due to its ability in scheduling appliances in a quick manner reduces the burden of data communication [12]. MGs play an active role in the market and energy producers and consumers are now known as prosumers which control and manage power demand. There are three main categories in the MG control strategy: centralized, decentralized and distributed (household-level). In a power system network, economic dispatch is centralized, as the data are collected from all the energy stations and are forwarded to the central controller unit. The decentralized control method has its control and can take decisions according to local power demands. It also provides stability in small-scale generating units. In the distributed control method, the information is shared among peer MGs by two-way communication to achieve optimisation.

In the present power sector, the use of MGs is increased due to the significant issue of power demand. However, one of the significant issues in the MG is the uncertainty of power supply due to the use of RESs. With the combination of ESS and DSM, power demand can reduce by scheduling the appliances according to the supply demand. DR's use changes the consumer's electric bill prices over time periods and results in electrical peak shaving. Recently, HEMS also became a part of the smart power system in the utilisation level. It gathers information from household appliances to optimize supply and demand problems. HEMS was also used to hold the household appliances hastily. HEMS manages appliances and energy supply to improve the power system's reliability.

\section{DROOP CONTROL METHOD}

MGs comprise more than one DG units, which can operate either in standalone or grid integrated mode, causing issues and creating challenges to operators. An MG comprises the solar PV system, the wind energy system and a battery energy storage system integrated into the utility grid through DC/DC buck/boost converter to extract maximum power from the 
RESs which are interfaced to the point of common coupling through the DC/AC power converter circuit. We connect local loads at PCC, as it can operate the MG in any of its modes. Droop control [26-27], became one of the most promising control techniques in the present MG scenario for parallel operation of converters due to the absence of a communication line between the DG units while minimizing the circulating current between converters [28]. The wireless droop controller is used mostly for load sharing as it has the advantage to avoid critical communications lines when two converters are operated in parallel. Another type of controller is master-slave droop controller (wired droop controller), which has the drawback that when more than two converters operate in parallel, the primary converter (acting as the master) is used to control the DC bus link voltage and transmits the reference signal to the other converters (slave converters). If the primary converter fails, the total system will shut down. In the voltage droop control, they interface each converted to a common point and each converter responds individually and calculates how much energy has to supply or consume and maintains the output voltage of the DC bus link voltage at its nominal value. However, the drawbacks of the conventional droop control are that its performance is poor with RESs and it has certain limits like slow transient response, voltage regulation, etc. Authors in [29] addressed a detailed review of droop control strategy. Voltage droop control regulates the inverter output voltage and frequency when sharing active and reactive power. Droop control is widely used in complex power generation and transmission. The line diagram of the transmission line (inverter connected to PCC) is shown in Figure 1, while (1) and (2) give the active and reactive powers transmitted across a lossless line.

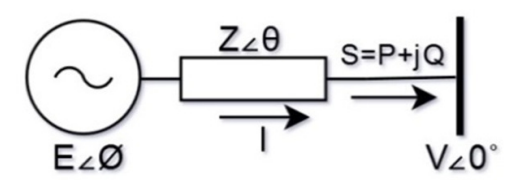

Fig. 1. Inverter connected at PCC

$$
\begin{gathered}
P=\frac{E V}{X} \sin \phi \\
Q=\frac{E V \cos \phi-V^{2}}{X} \\
f=\frac{P V}{E V} \\
(E-V) \approx \frac{Q X}{E}
\end{gathered}
$$

Assuming the power angle is tiny, from (3) and (4) it is derived that the reactive power mainly depends on the power angle and moves through the limits of the output voltage. Output voltage amplitude and frequency can define the droop characteristics shown in Figure 3. We use this method to control the active power flow by taking frequency as a set point from each inverter unit, instead of considering the inverter output power.

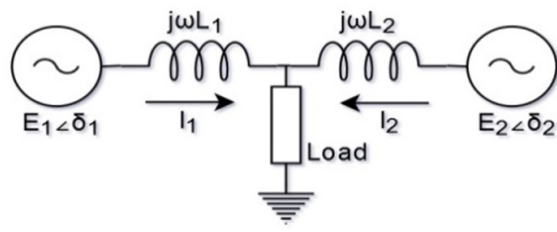

Fig. 2. Two inverters connected to the load

$$
\begin{gathered}
\omega=\omega^{*}-K_{1} P \\
E=E^{*}-K_{2} Q
\end{gathered}
$$

In grid-connected mode we have:

$$
\begin{aligned}
& \omega=\omega^{*}-K_{1}\left(P-P^{*}\right) \\
& E=E^{*}-K_{2}\left(Q-Q^{*}\right)
\end{aligned}
$$
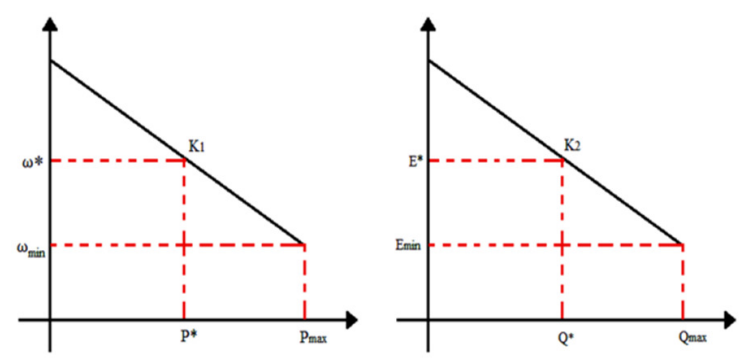

Fig. 3. Voltage droop controller

In (5) and (6), $\omega^{*}$ and $E^{*}$ are the set points for the output voltage amplitude and the angular frequency at the no-load condition and $K_{1}$ and $K_{2}$ are the droop controller gain coefficients for amplitude and frequency. $P^{*}$ and $Q^{*}$ are the reference setpoints obtained from real power vs frequency and from reactive power vs voltage amplitude [14]. We represent these droop controller equations in Figure 3. When the frequency falls from its limits, the output power generated is increased, something that shows that increase in the load demand and requirement of more active power. However, when two converters operate in parallel with the same droop control characteristics a fall in the frequency occurs which results in a simultaneous increase in the active output power. The increase in the output power counteracts the fall in frequency and the system settles down in a steady-state point on droop controller characteristics. So, the droop controller allows the converters that operate in parallel to share the load with no disturbances. We applied this technique to the voltage droop controller shown in Figure 4 to maintain the DC bus link voltage. However, the design and stability of a DC bus link voltage controller are not discussed thoroughly in this paper. 


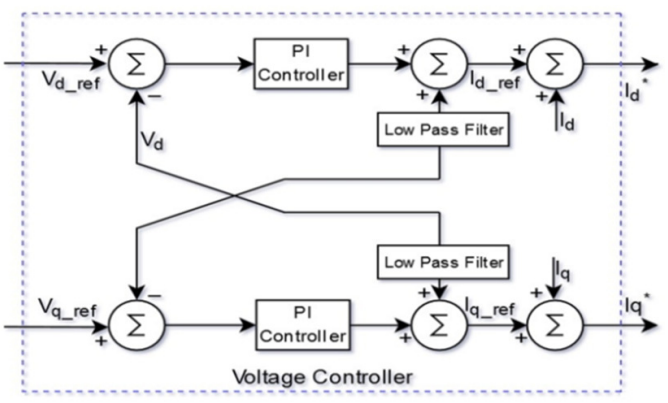

Fig. 4. Voltage droop controller

\section{SiMULATION MODEL, RESULTS, AND DISCUSSION}

\section{A. Microgrid Configuration}

The overall system configuration of the proposed MG is shown in Figure 5.

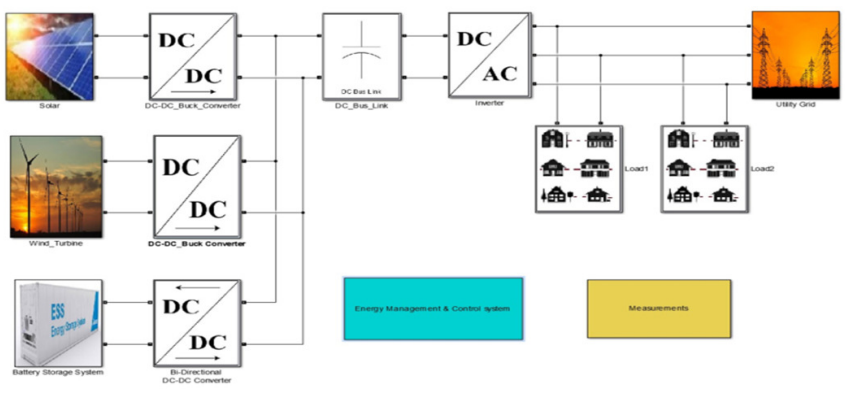

Fig. 5. Simulink MG model

TABLE I. SYSTEM SPECIFICATIONS

\begin{tabular}{|c|c|c|}
\hline \multicolumn{3}{|c|}{ Simulation result parameters } \\
\hline Parameters & Symbol & Output ratings \\
\hline \multicolumn{3}{|c|}{ Specification of the solar photovoltaic module } \\
\hline Maximum PV power & $\overline{\mathrm{P}_{\mathrm{PV}}}$ & $14 \mathrm{KW}$ \\
\hline Maximum PV voltage & $\mathrm{V}_{\mathrm{PV}}$ & $500 \mathrm{~V}$ \\
\hline Maximum PV current & $I_{\mathrm{PV}}$ & $28 \mathrm{~A}$ \\
\hline Open circuit voltage & $\mathrm{V}_{\mathrm{OC}}$ & $\begin{array}{l}32.9 \mathrm{~V} \text { of each cell }(360 \\
\text { cells in } 1 \text { module) }\end{array}$ \\
\hline Short circuit current & $\mathrm{I}_{\mathrm{SC}}$ & 8.21A (Single Module) \\
\hline \multicolumn{3}{|c|}{ Specification of Wind Turbine } \\
\hline Maximum power & $\mathrm{P}_{\mathrm{WT}}$ & $14 \mathrm{KW}$ \\
\hline Maximum voltage & $\mathrm{V}_{\mathrm{WT}}$ & $500 \mathrm{~V}$ \\
\hline Maximum current & $\frac{I_{W T}}{2}$ & $28 \mathrm{~A}$ \\
\hline \multicolumn{3}{|c|}{ Specification of BESS (lead-acid battery) } \\
\hline Battery voltage & $\mathrm{V}_{\text {Bat }}$ & $200 \mathrm{~V}$ \\
\hline Battery rated capacity & $\mathrm{C}_{\mathrm{Ah}}^{\mathrm{r}}$ & $40 \mathrm{Ah}$ \\
\hline Maximum battery capacity & $\mathrm{C}^{\max }{ }_{\mathrm{Ah}}$ & $41.66 \mathrm{Ah}$ \\
\hline Fully discharge current & $\mathrm{V}_{\mathrm{ch}, \mathrm{I}} \mathrm{I}_{\mathrm{dch}}$ & $217.76 \mathrm{~V}, 8 \mathrm{~A}$ \\
\hline \multicolumn{3}{|l|}{ Other System Specifications } \\
\hline DC bus link voltage & $\mathrm{V}_{\mathrm{dc}}$ & $500 \mathrm{~V}$ \\
\hline Connected Load-1 & $\mathrm{P}_{\mathrm{LI}}$ & $3 \mathrm{KW}$ \\
\hline Connected Load-2 & $\overline{\mathrm{P}_{\mathrm{L} 2}}$ & $3 \mathrm{KW}$ \\
\hline
\end{tabular}

The system comprises a common DC bus and an AC bus of $500 \mathrm{~V}$. Various components are connected to the DC bus, and different loads are supplied by the AC bus for residential or commercial use. Solar PV and Wind Turbine power are considered as the main sources, grid power as the primary source of power supply, and BSS is considered as the backup source for peak load demands. We have connected the solar PV source with the help of a buck converter, and Wind Turbine power is first converted to DC with the help of a rectifier circuit and is connected to the bus using a buck converter. A BSS with a rated capacity listed in Table I is also connected to the DC-link bus by a bi-directional converter. By using a $\mathrm{DC} / \mathrm{AC}$ converter, the entire DC supply is inverted to AC and used to feed the local loads at PCC while integrated to the utility grid.

\section{B. Results and Discussion}

The performance of the hybrid model designed with PV, Wind Turbine, and ESS is verified with the use of the variablestep solver (ode23tb) in Simulink for a time interval of $1 \mathrm{~s}$. The parameters of the model are listed in Table I. Considering the integration of solar and wind power to a utility grid, we mainly concentrated on the DC bus link voltage when two or more energy sources are interconnected with each other. As RES depends on geographical and weather conditions, the output power will fluctuate with varying solar irradiance and wind speed. To extract maximum power from these sources, a DC/DC converter with the help of a particular MPPT technology is used. However, when interconnecting two sources the voltage at the DC bus link is going to fluctuate due to the flow of circulating current in the system. When there is a change in irradiance or wind speed or a change in load, the output obtained from these sources will also change, affecting the bus voltage. To keep the DC bus link voltage, we used a droop control strategy. We considered the voltage droop controller shown in Figure 4, and we modelled both solar and wind energy sources at 500V, as shown in Figures 6 and 7.

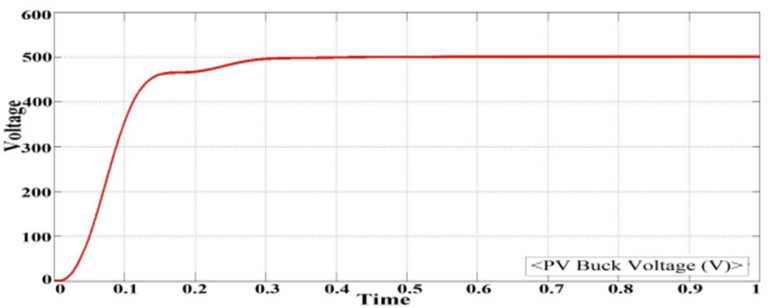

Fig. 6. Solar energy DC output voltage

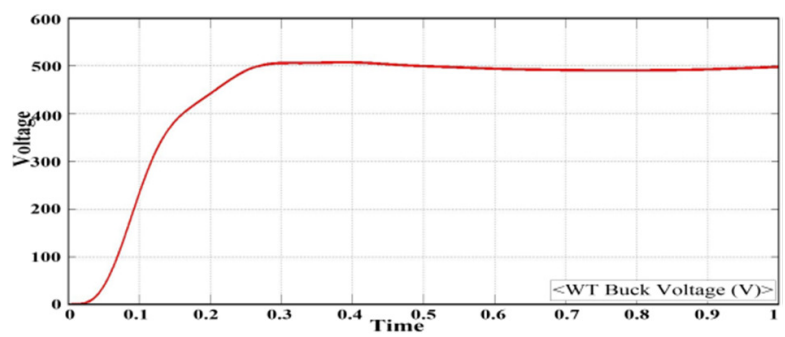

Fig. 7. Wind energy DC output voltage

Simulations were done with changes in wind speed and solar irradiance. Wind speed was considered to range between $8-12 \mathrm{~m} / \mathrm{s}$ and solar irradiance between $700-1000 \mathrm{~W} / \mathrm{m}^{2}$. We mainly focused on providing a constant voltage at the DC bus link, which is connected to the RESs and to achieve power balance by maintaining it at a constant value. However, the 
voltage regulation of the system is affected by various disturbances, e.g. interconnecting two or more sources, weather changes, changing in loads, etc.. The droop coefficients $K_{l}$ and $K_{2}$ take the small values of 0.32 and 0.7 for all generating units in this model for simplicity (as we are concentrated on voltage) and a reference voltage of $500 \mathrm{~V}$ is set in the controller. In Figure 8, the purple line shows the DC bus link voltage when two sources are interconnected and the voltage is maintained at $500 \mathrm{~V}$. By maintaining the DC bus link voltage at a constant value, the MG operation under grid-connected mode at a constant load of $6 \mathrm{KW}$ and with variation in the solar irradiation and wind speed, the output voltage of inverter and active and reactive power of the system are shown in Figures 9 and 10 . We observe that the droop controller took less than $0.2 \mathrm{~s}$ to maintain $500 \mathrm{~V}$ with $K_{2}=0.7$.

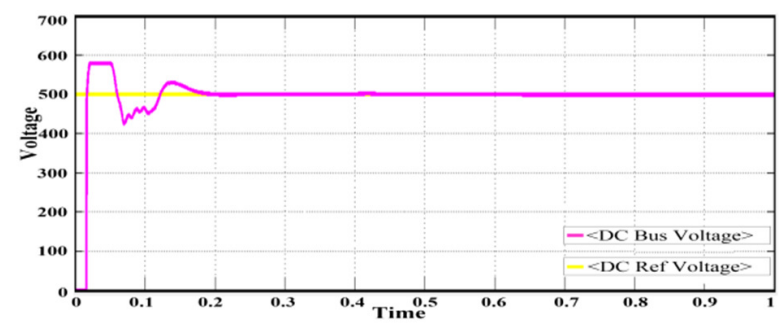

Fig. 8. DC bus-link voltage

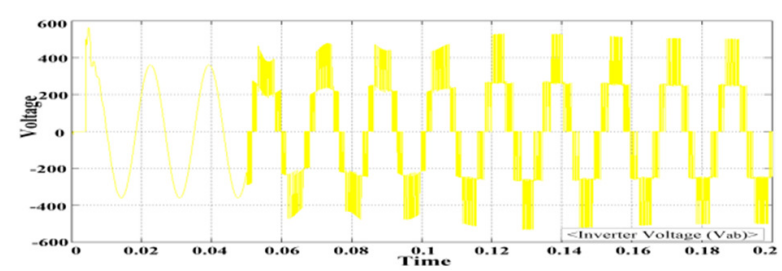

Fig. 9. Inverter line voltage (Vab)

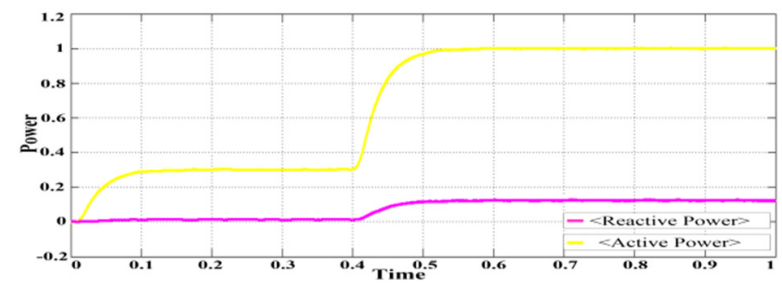

Fig. 10. Active and reactive power of the system

\section{CONCLUSION}

Renewable energy sources depend on environmental conditions and can cause variations in the output voltage, which may lead to changes in the DC bus link voltage and increase of the circulating currents in parallel operating converters. The flow of circulating currents will affect the degradation of battery state of charge. The main aim of control is to keep the DC bus link voltage constant with the help of a voltage droop controller by taking reference setpoints from the voltage droop characteristics. Simulations were conducted with varying wind speed and solar irradiation. The results show that the design of the proposed MG with voltage droop control can successfully maintain the DC bus link voltage at a constant value throughout the system operation. The droop controller allows the converters to share the currents with no interdisturbance on controlling the load when they operate in parallel. This control method also reduces the active and reactive power variation by maintaining reference set points from output voltage magnitude in a stable condition. This paper mainly focused on demand-side management and voltage droop control due to its simplicity in operation, which is used to interconnect more than one distributed generation sources in a microgrid.

\section{REFERENCES}

[1] Wikipedia, Electricity sector in India, available at: https://en.wikipedia.org/wiki/Electricity_sector_in_India

[2] Wikipedia, Renewable energy in India, available at: https://en.wikipedia.org/wiki/Renewable_energy_in_India

[3] T. V. Krishna, M. K. Maharana, C. K. Panigrahi, "Challenges in integrating renewable sources into a utility grid", International Journal of Innovative Technology and Exploring Engineering, Vol. 9, No. 3, pp. 91-97, 2020

[4] A. Merabet, K. T. Ahmed, H. Ibrahim, R. Beguenane, A. M. Y. M. Ghias, "Energy management and control system for laboratory scale microgrid based wind-PV battery", IEEE Transactions on Sustainable Energy, Vol. 8, No. 1, pp. 145-154, 2017

[5] H. Kanchev, D. Lu, F. Colas, V. Lazarov, B. Francois, "Energy management and operational planning of a microgrid with a PV-based active generator for smart grid applications", IEEE Transactions on Industrial Electronics, Vol. 58, No. 10, pp. 4583-4592, 2011

[6] P. Palensky, D. Dietrich, "Demand side management: Demand response, intelligent energy systems, and smart loads", IEEE Transactions on Industrial Informatics, Vol. 7, No. 3, pp. 381-388, 2011

[7] R. Debnath, D. Kumar, D. K. Mohanta, "Effective demand side management (DSM) strategies for the deregulated market environments", Conference on Emerging Devices and Smart Systems, Tiruchengode, India, March 3-4, 2017

[8] S. Pholboon, M. Sumner, P. Kounnos, "Adaptive power flow control for reducing peak demand and maximizing renewable energy usage", International Electrical Engineering Congress, Pattaya, Thailand, March 8-10, 2017

[9] P. Pathomchaiwat, B. Neammanee, "Control of power management in the renewable energy system by using flywheel energy storage", 14th International Conference on Electrical Engineering/Electronics, Computer, Telecommunications and Information Technology, Phuket, Thailand, June 27-30, 2017

[10] J. Fang, Y. Tang, H. Li, X. Li, “A battery/ultracapacitor hybrid energy storage system for implementing the power management of virtual synchronous generators", IEEE Transactions on Power Electronics, Vol. 33 , No. 4, pp. 2820-2824, 2018

[11] N. Javaid, I. Ullah, M. Akbar, Z. Iqbal, F. A. Khan, N. Alrajeh, M. S. Alabed, "An intelligent load management system with renewable energy integration for smart homes", IEEE Access, Vol. 5, pp. 13587-13600, 2017

[12] D. Gosselin, J. Jiang, H. Sun, "Household level distributed energy management system integrating renewable energy sources and electric vehicles", IEEE 85th Vehicular Technology Conference, Sydney, Australia, June 4-7, 2017

[13] A. Kumar, N. K. Paliwal, A. K. Singh, P. Kumar, S. Sehgal, N. K. Singh, R. K. Singh, "Optimal energy management of hybrid power system with two different battery models", International Electrical Engineering Congress, Pattaya, Thailand, March 8-10, 2017

[14] E. Barklund, N. Pogaku, M. Prodanovic, C. H. Aramburo, T. Green, "Energy management in autonomous microgrid using stabilityconstrained droop control of inverters", IEEE Transactions on Power Electronics, Vol. 23, No. 5, pp. 2346-2352, 2008

[15] Y. Ozturk, D. Senthilkumar, S. Kumar, G. Lee, “An intelligent home energy management system to improve demand response", IEEE Transactions on Smart Grid, Vol. 4, No. 2, pp. 694-701, 2013 
[16] Y. Riffonneau, S. Bacha, F. Barruel, S. Ploix, "Optimal power flow management for grid connected PV systems with batteries", IEEE Transactions on Sustainable Energy, Vol. 2, No. 3, pp. 309-320, 2011

[17] S. Pradhan, D. Mishra, M. K. Maharana, "Energy management system for micro grid pertaining to renewable energy sources: A review", International Conference on Innovative Mechanisms for Industry Applications, Bangalore, India, February 21-23, 2017

[18] A. Kumar, Y. Deng, X. He, P. Kumar, R. C. Bansal, "Energy management system controller for a rural microgrid", The Journal of Engineering, Vol. 2017, No. 13, pp. 834-839, 2017

[19] I. D. S. Suarez, G. O. Plata, G. C. Caicedo, "Microgrid's energy management systems: A survey", 12th International Conference on the European Energy Market, Lisbon, Portugal, May 19-22, 2015

[20] J. Zhang, L. Huang, J. Shu, H. Wang, J. Ding, "Energy management of PV-diesel-battery hybrid power system for island stand-alone microgrid”, Energy Procedia, Vol. 105, pp. 2201-2206, 2017

[21] S. M. Sichilalu, H. Tazvinga, X. Xia, "Integrated energy management of grid-tied-PV-fuel cell hybrid system", Energy Procedia, Vol. 103, pp. $111-116,2016$

[22] Y. Riffonneau, S. Bacha, F. Barruel, A. Delaille, "Energy flow management in grid connected PV systems with storage-A deterministic approach", IEEE International Conference on Industrial Technology, Gippsland, Australia, February 10-13, 2009

[23] P. Zhang, Y. Liu, M. Gu, "Simulation technique in design of non-gridconnected wind power simulation system", World Non-Grid-Connected Wind Power and Energy Conference, Nanjing, China, November 5-7, 2010

[24] B. V. Solanki, K. Bhattacharya, C. A. Canizares, "A sustainable energy management system for isolated microgrids", IEEE Transactions on Sustainable Energy, Vol. 8, No. 4, pp. 1507-1517, 2017

[25] D. B. Nguyen, J. M. A. Scherpen, F. Bliek, "Distributed optimal control of smart electricity grids with congestion management", IEEE Transactions on Automation Science and Engineering, Vol. 14, No. 2, pp. 494-504, 2017

[26] Z. Shuai, S. Mo, J. Wang, Z. J. Shen, W. Tian, Y. Feng, "Droop control method for load share and voltage regulation in high-voltage microgrids", Journal of Modern Power Systems and Clean Energy, Vol. 4, No. 1, pp. 76-86, 2016

[27] A. Khaledian, M. A. Golkar, "Analysis of droop control method in an autonomous microgrid", Journal of Applied Research and Technology, Vol. 15, No. 4, pp. 371-377, 2017

[28] T. V. Krishna, M. K. Maharana, C. K. Panigrahi, "Design and control of a droop controller for minimising circulating current in DC microgrid", International Conference on Recent Trends in Computing, Communication and Networking Technologies, Tamilnadu, India, October 18-19, 2019

[29] U. B. Tayab, M. A. B. Roslan, L. J. Hwai, M. Kashif, "A review of droop control techniques for microgrid", Renewable and Sustainable Energy Reviews, Vol. 76, pp. 717-727, 2017

[30] S. Meziane, O. Feddaoui, R. Toufouti, "Modelling and simulation of hybrid wind-diesel power generation system", International Journal of Renewable Energy, Vol. 8, No. 2, pp. 49-58, 2013

[31] D. K. Dhaked, Y. Gopal, D. Birla, "Battery charging optimization of solar energy based telecom sites in India", Engineering, Technology \& Applied Science Research, Vol. 9, No. 6, pp. 5041-5046, 2019

[32] M. L. L. Tuballa, M. L. S. Abundo, "Operational impact of RES penetration on a remote diesel-powered system in west Papua, Indonesia", Engineering, Technology \& Applied Science Research, Vol. 8, No. 3, pp. 2963-2968, 2018

[33] M. Hussain, M. H. Baloch, F. Umer, A. H. Memon, N. K. Pathan, "Maximum power tracking system based on power electronic topology for wind energy conversion system applications", Engineering, Technology \& Applied Science Research, Vol. 8, No. 5, pp 3392-3397, 2018 